\title{
Creativity Level of Hearing Impaired and Hearing Students of Federal College of Education
}

\section{Dorcas Sola Daramola}

Department of Social Sciences Education, Faculty of Education, University of Ilorin, Nigeria, daramola.ds@unilorin.edu.ng

\section{Muhinat Bolanle Bello}

Department of Social Sciences Education, Faculty of Education, University of Ilorin, Nigeria, bello.mb@unilorin.edu.ng

\section{Abdul Raheem Yusuf}

Department of Social Sciences Education, Faculty of Education, University of Ilorin, Nigeria, yusuf.a@unilorin.edu.ng

\section{Ismaila Oteikwu O. Amali}

Department of Social Sciences Education, Faculty of Education, University of Ilorin, Nigeria,amali.ioo@unilorin.edu.ng

This study investigated creativity Level of Hearing Impaired and Hearing Students of Federal College of Education in Oyo. Specifically, the study investigated the creativity level of hearing and hearing-impaired students. Also, a relationship between gender and onset of hearing loss and students' creativity level were found out. A descriptive survey design was adopted for this study. A purposive sampling technique was used to sample a total of 248 second year students Nigerian Certification in Education (NCE II) of the School of Education who participated in the study. A researcher-designed questionnaire with a reliability coefficient of 0.76 was used to collect data for the study. The Findings showed that the creativity level of hearing-impaired students is significantly higher compared to their hearing peer. It was revealed that female hearing impaired students significantly show a higher level of creativity than their male peer. Also, post-lingual hearing-impaired students are significantly higher in creativity level than their pre-lingua peers. Based on these findings, it was recommended that mainstreaming approach of providing education services adopted by Federal College of Education in Oyo should be strengthened and adopted in all institution where hearing and hearingimpaired attend.

Keywords: creativity, hearing impaired, critical thinking, institutions, mainstreaming

Citation: Daramola, D. S., Bello, M. B., Yusuf, A. R., \& Amali, I. O. O. (2019). Creativity Level of Hearing Impaired and Hearing Students of Federal College of Education. International Journal of Instruction, 12(1), 1489-1500. https://doi.org/10.29333/iji.2019.12195a 


\section{INTRODUCTION}

Creativity is the act of turning new imaginative ideas into reality. Creativity is characterized by the ability to perceive the world in new ways, to find hidden patterns, to make connections between seemingly unrelated phenomenons and to generate solutions. Creativity involves two processes: thinking, then producing. The ability to generate novel ideas and think creatively about problems has long been considered an important skill for individuals, as well as for organizations and societies. Individuals' creative problem solving can generate new products and services, which in turn create jobs for others (Sternberg, 1999). Creativity is a crucial aspect of intellectual operation. To certain people, creativity is sensed as a gift or trait, not only this but also a meaningful factor that gears the human race on the way to success. Members of society deemed creative are thought to be unique and are expected to contribute to the betterment of society beyond what the average person can. People found to be highly creative have made noteworthy contributions throughout history. Notable examples of these beings who have contributed immensely to the development of their society include Albert Einstein, Galileo, Watt, Picasso, Leonardo Da Vinci. Continued advancement of culture and society relies on better understanding individual differences in the development and application of creativity.

Creative thinking allows people to solve problems effectively and also to remain flexible so that they can cope with the advantages, opportunities, technologies, and changes that are parts of their day-to-day lives (Mumford \& Gustafson, 1988). Human society is in great need of new inventions, firsthand scientific discoveries and novel social programs to bring about advancement, and various organizations need them to adapt to changing environments and succeed in the marketplace (Oldham \& Cummings, 1996). A creative individual can therefore be regarded as that male or female endowed with the standard attributes of an active mind. These attributes of a creative being will encompass; the ability to redefine conditions and preserve penetrative mental techniques; frequency of thoughts, the ability of mental strategy and; originality. Creative thinking capabilities were found helpful in improving the performances and productiveness of students either hearing impairment or normal, everyday of their numerous fields mainly within the regions of fine artwork, language, music and recently in the sciences.

Hearing impairment is defined as partial or total inability to hear. It is impairment typified by total or partial inability to receive sound and interpret speech as meaningful messages. Since hearing impairment embodies people with varying levels of hearing loss, on this ground it is likely that the affected individual may be deaf. It is of note that the early stage of hearing impairment could be present during foetal development, which is known as congenital (pre-lingual) or acquired (post-lingual).

Education of hearing impaired people has existed for a considerable length of time. While there had been a major number of effective hearing-hindered people, there have moreover been a considerable lot of them which have never again get an extraordinary training, shared decent connections, or had agreeable professions. This shows that there is a lacuna, and to fill this gap, instructions for hearing impaired individuals must be 
agreeable to their needs. The child with hearing impairment learns greatly by observation.

The roles of language in total development of man can never be over-emphasized. No wonder hearing impaired individuals are vulnerable to postponement in language development and conversation, poor academic accomplishment, creativity, have a problem of interpersonal relationship cum emotional development. It is explicit that all individuals with hearing impairment have a critical problem of language deprivation (Olawuyi, 2000). The boundless of poor thinking among students with hearing debilitation can be ascribed to their listening ability misfortune and to the denying condition in which they frequently develop. To support this, Olanrewaju, (2014) observed hearing-impaired tertiary institution students in two states in Nigeria and discovered that they were poor in critical thinking, contrary to this, Kaltsounis (1971) revealed that deaf school-age children performed superior to hearing kids in the aspects of fluency, adaptability, elaboration, and creativity. Osakwe (2010) insisted that regardless of the way disabled students are being defamed, their innovativeness capacity still remains undoubted. Hearing impairment could be named as heterogeneous issue containing various intra and relational qualities. For instance, elements such as onset, type and degree of hearing loss, gender and some other home background issues could affect the creativity level of the victims.

By onset of hearing loss we mean an exact time that critical hearing loss happens. The single important distinction for delineating persons with hearing disability is between pre-lingual and post-lingual occurrences of hearing loss. Pre-lingual loss of hearing happens before language acquisition while post-lingual loss occurs after spoken language has been procured. The previous can't naturally procure speech as the hearing individuals do. The latter mentioned, be that as it may, having developed speech before supporting hearing loss can utilize speech along these lines for learning and social purposes. Losing hearing at the onset (either before birth or before speech acquisition) is more constraining than losing hearing further down the road particularly after the speech has been obtained and identity created. Impacts of early life loss of hearing are felt in the whole personality of the casualty. The pre-lingual hearing impaired individual have little chance to impart genuinely in instructive or social settings. Kauffman, (2003) opined that post-lingual hearing disables have a tendency to be able to be more imaginative than the pre-lingual hearing disable in light of the fact that the previous has better learning data sources and yields because of the correspondence aptitude he/she had procured before maintaining the hearing loss. Likewise, Olanrewaju, (2014) submitted that there was a noteworthy contrast in the critical thinking skills of students with hearing impairment, post-lingual hearing disables essentially improved the situation in critical thinking than their pre-lingual associate. In the same vein, Ademokoya (2007) submitted that post-lingual hearing disabled students were superior to their pre-lingually hearing-disabled colleagues.

It has been seen that different natural contrasts in human make up, for example, are contrasts inalienable in male and female understudies might be in charge of a few incongruities in language use and school performance. Since no two individuals are the 
same in physical and intellectual attributes, then uniform performance in some endeavour should not be expected from a male and female individual. Book (1972) observed that boys tend to excel more in tasks that require critical reasoning than girls. Olawuyi (2000), submitted that there is a significant difference in the reasoning abilities of primary school pupils based on gender. On the contrary Olanrewaju (2014) submitted that there was no significant difference in the critical thinking of students with hearing impairment on the basis of gender.

Overall, the lack of differences in genders is found in many creativity studies. Baer and Kaufman (2008) then argued that any gender differences in creativity probably stems from an environmental factor. They also believed in "relative equality in creative ability" between the genders (Baer \& Kaufman, 2008). However, several studies have revealed that a gender difference in creative performance was found. Kaufman (2006) examined self-report measures of creativity in 3,553 students across different domains. He found that females rated themselves higher on social-communications and on the visual-artistic factor, while males rated themselves higher on the science-analytic factor and sports. However, there were no differences on the verbal-artistic factor. These results are consistent with research on gender and self-reported intelligence and this selfassessment is also consistent with gender stereotypes. Urban and Jellen, (1996) carried out a study on gender differences in creativity among school children. Their results showed that boys outperformed girls in boundary-breaking thinking, whereas girls were better in thoroughness of thinking. They suggested both genders have their strengths and weaknesses in terms of different dimensions of creative thinking.

The discrepancy in creativity, in regard to gender, was also found in different cultures. Oral (2007) utilized two different tests - the Alternate Uses Test and the Consequences Test to measure creativity of school children in Turkey. The results showed no gender differences on the Alternate Uses Test, but females scored higher on the Consequences Test. Cheung and Lau (2010) used the Wallach-Kogan Creativity Tests on schoolchildren in Hong Kong. Their results showed middle school girls outperformed boys in several dimensions of creativity. By canonical correlation analysis, Ai (1999) found Spanish male and female students showed different aspects of creativity related to academic achievement. For male students, flexibility was the predominant factor that related to academic performance, while in females, fluency and elaboration were more important factors. He suggested that the gender differences in creativity could be in part influenced by gender roles. According to Jonathan (2002), the correlation to lifetime creative accomplishment is more than three times stronger for childhood creativity than childhood IQ.

\section{Statement of the Problem}

A growing number of students with hearing impairment are being granted access to higher education in Nigeria due to the adoption of inclusive educational policies. However, available statistics indicate that participation by students with hearing impairments in higher education remains low. This is due to what they are experiencing in higher education. However, studies has revealed that of the students with hearing impairment who enter higher education, many do not graduate successfully due to a 
variety of factors, such as lack of support and unfriendly learning environments among others. Also, there is frequently reported fact of academic achievement gap between students who hear and those with a hearing impairment in school. The question raised by researchers and academia is that, could it be that the hearing impaired and hearing students do not differs in their creativity level, thinking level, study habit and intelligent level?

\section{Purpose of the Study}

The study investigated factors affecting the students' creativity level such as hearing status and onset of hearing loss and gender, in the teacher training institute for the special needs (Federal College of Education Special, Oyo). Specifically, the study examines:

- $\quad$ Level of creativity of hearing impaired students of Federal College of Education in Oyo.

- Level of creativity of hearing students of Federal College of education in Oyo.

- Whether there is a significant difference in the level of creativity of hearing and hearing-impaired students of Federal College of Education in Oyo (base on status).

- If there is a significant difference in the creativity level of a hearing- impaired student of Federal College of Education in Oyo based on gender and onset of hearing loss (degree of hearing loss).

Three research null hypotheses were therefore formulated and tested in this study.

Ho$_{1}$ : There is no significant difference in the level of creativity of students of Federal College of Education in Oyo on the basis of Status.

$\mathbf{H o}_{2}$ : There is no significant difference in the creativity level of the hearing-impaired student of Federal College of Education in Oyo based on gender.

Ho $:$ There is no significant difference in the creativity level of hearing impaired students of the Federal College of Education in Oyo based on onset of hearing impairment.

\section{METHOD}

\section{Research Design}

The study adopted a descriptive survey design which examines the creativity level of hearing-impaired and hearing students of Federal College of Education Special, in Oyo. The descriptive survey, according to Daramola (2006), is the systematic attempt to describe the characteristics of a given population or areas of interest. In a similar vein, Best and Kahn (2006) observe that descriptive survey is a research design which aims at describing, recording, analyzing and interpreting existing conditions that yield valid and reliable education research results. Similarly, Sambo (2008) states that descriptive research aims at estimating as precisely as possible the attributes of a population. Nevertheless, this researcher is interested in describing an educational condition the way it is as at the time of the investigation. This afforded the researcher direct contacts with the respondents so as to obtain the needed data. Therefore, the researcher described, 
precisely, the results by recording, analyzing and interpreting the data. All these justify the use of the descriptive survey method.

\section{Sample and Sampling techniques}

All the students (hearing and hearing -impaired) of Federal College of Education Special in Oyo, constituted the population for the study while students at the second year (NCE II) constituted the target population. There are a total 2,101students in the sampled school (Data base of Federal College of Education, 2017). Out of which a multistage sampling technique was adopted in sampling respondents for this study. At first, a purposive sampling technique was employed in the selection of second year students of Nigeria Certificate in Education (NCE) of both hearing and hearing-paired students. The reason is that these sets of students have been exposed to the teaching and learning activities in the school for at least a period of one academic session in the college. This is in line with Sambo (2008) who maintains that a researcher can purposively sample respondents for use if the researcher finds any attribute of interest in the population. Secondly, out of six schools in the college, school of education was purposively sampled for the study, this is due to the fact that school of education housed all other students from the various schools for general education courses (such as the school of Business, Vocation, Language, Social Sciences among others). There are 687 students in the NCE 2 class out of which a total of 248 consisting of 102 hearing and 146 hearing impaired were sampled for the study, using simple random sampling techniques. This is in line with The Research Advisor (2006) Table for selecting the sample, that stated it clearly that 248 is accurate for selection in a sample population of $600-700$ at the confidence level of $95 \%$ and $5.0 \%$ margin of error.

\section{Instrumentation}

Researchers-designed questionnaire entitled "Questionnaire on Creativity level of Students with Hearing- impaired and Hearing" was used to collect data for the study. The questionnaire has two sections, section A elicited students' biographic information while section B contained 20 items with 4 Point-Likert type response formats with Strongly Agree (SA-4points), Agree (A-3points), Disagree (D-2points) and Strongly Disagree (SD-1point) as options for positive responses while reversed is the case for negative response. The items of the questionnaire were validated by experts in the Unit of Educational Research, Measurement and Evaluation, Department of Social Sciences Education, Faculty of Education, University of Ilorin. In line with Ujo (2000) who stated that the standard procedure for validation of any research instrument is by giving it to a panel of experts to determine if items actually elicit the information they were meant to. The reliability of the instrument was ascertained using split-half method. Alpha Cronbach reliability coefficient of 0.76 was obtained after Spearman Brown formula was applied.

\section{Procedure for Data Collection}

The researcher approached the College Management (The Registrar) with a letter of introduction from the Head of Department of Social Sciences Education, Faculty of Education, University of Ilorin, Ilorin, Nigeria to seek permission to administer the 
instrument to the respondents. The administration of the questionnaire was done by all the researchers. The completed copies of the instrument were immediately returned to the researchers.

\section{Data Analysis Techniques}

The data collected were analyzed using descriptive statistics (means and standard deviation). The two research questions were answered using mean and standard deviation while student t-test statistical was used to test the two hypotheses formulated at 0.05 alpha level using computer-assisted SPSS, 20.0 version. Independent t-test was considered appropriate for the analyses of the hypotheses since there are two groups of respondents involved (hearing-impaired and hearing). According to Sambo (2008), two-sample t-test is a statistical tool that could be used to determine whether the unknown means of two populations are different from each other based on the independent samples from each population, especially when the samples are obtained from a single population that has been randomly divided into two subgroups, with each subgroup subjected to one or two treatments or from two separate populations. The data collected in this study were in continuous form thus, this necessitated adoption of t-test statistical tools. This is because some data could be considered in either way. For example, a person's rating of someone else's opinion or perception on a 4 or 5 - point scale is considered a continuous data.

\section{Ethical Consideration of the Study}

The researchers first and foremost make sure that a consent letter was obtained from the respondents and the College management on the basis of informed consent. The consent letter contained necessary information and assurances which enable the respondents to understand the implications of participating in the study. In order to address ethical considerations aspect of this study, the researchers allow for the voluntary participation of respondents (hearing-impaired and hearing students) in the study. Moreover, the students were given the right to withdraw from the study at any stage if they wish to do so.

The researchers' designed questionnaire used in this study was free of obnoxious language. And the high level of respondents' privacy and anonymity was ensured, that was why names and other identification of the respondent's columns were not indicated in section A of the questionnaire. The researchers ensured that all the authors cited in the study were adequately acknowledged to maintain a high level of originality. While processing the data collected in the field, a maximum level of research integrity (objectivity) ensured from the coding of data to the analysis, also to the interpretation and discussion.

\section{FINDINGS}

Research Questions 1: What is the level of creativity of hearing impaired students of Federal College of Education in Oyo?

Information collected on hearing impaired students' creativity was subjected to mean analysis. 
Table 1

Creativity level of hearing impaired students of Federal College of Education in Oyo

\begin{tabular}{llllll}
\hline & $\mathrm{N}$ & Minimum & Maximum & Mean & SD \\
\hline CREATIVITY & 146 & 45.00 & 78.00 & 64.0690 & 13.79151 \\
\hline
\end{tabular}

Table 1 revealed the minimum creativity level of hearing impaired students as 45.00, maximum creativity level as 78.00, the mean is 64.0690 and standard deviation as 13.791. It implies that creativity level of hearing-impaired students is above average.

Research Questions 2: What is the level of creativity of hearing students of the Federal College of Education in Oyo?

Information collected on students' creativity was subjected to mean analysis.

Table 2

Creativity level of hearing students of Federal College of Education in Oyo

\begin{tabular}{llllll}
\hline & $\mathrm{N}$ & Minimum & Maximum & Mean & SD \\
\hline CREATIVITY & 102 & 46.00 & 68.00 & 61.1222 & 5.89578 \\
\hline
\end{tabular}

Table 2 revealed 46.00 and 68 as the minimum and maximum creativity level of hearing students, with mean of 61.1222 and standard deviation of 5.89578. This implies that the creativity level of hearing students is above average.

\section{Hypotheses Testing}

Ho1: There is no significant difference in the level of creativity of hearing and hearing-impaired students of FederalCollege of Education in Oyo.

Hearing and hearing-impaired students of Federal College of Education in Oyo level of creativity were compared using t-test statistics and the results are on Table 3.

Table 3

t-test analysis on difference in the level of creativity of hearing and hearing-impaired students of Federal College of Education in Oyo.

\begin{tabular}{llllllll}
\hline Variable & $\mathrm{N}$ & Mean & St.d & df & t & p-value & Decision \\
\hline Hearing students & 102 & 61.12 & 5.895 & & & & \\
\hline & & & & 148 & 1.791 & 0.03 & $\mathrm{~S}$ \\
\hline $\begin{array}{l}\text { Hearing impaired } \\
\text { Students }\end{array}$ & 146 & 64.06 & 13.79 & & & & \\
\hline
\end{tabular}

Table 3 showed the t-test calculated value is 1.791 which is significant at 0.05 alpha level. Thus, the null hypotheses one is rejected since p-value 0.03 is less than 0.05 alpha level $(0.03<0.05)$. It implies that there is no significant difference in the creativity of hearing and hearing-impaired students of Federal College of Education Oyo. Hearing impaired students with a higher mean of 64.06 significantly have higher creativity level.

Ho2: There is no significant difference in the creativity level of a hearing-impaired student of Federal College of Education in Oyo based on gender. 
Level of creativity of male and female hearing impaired students of Federal College of Education in Oyo was compared using t-test statistics and the results are in Table 4.

Table 4

t-test analysis of creativity level of hearing impaired students of Federal College of Education in Oyo based on gender.

\begin{tabular}{llllllll}
\hline Variable & $\mathrm{N}$ & Mean & St.d & df & t & p-value & Decision \\
\hline Male & 21 & 61.48 & 9.432 & & & & \\
\hline & & & & 58 & 1.080 & 0.028 & $\mathrm{~S}$ \\
\hline Female & 39 & 65.54 & 15.671 & & & & \\
\hline
\end{tabular}

Table 4 shows the calculated t-value 1.080 with a $\mathrm{p}$ - value 0.028 . At alpha level of 0.05 , the null hypothesis is rejected because the calculated p-value is less than 0.05 alpha level $(0.028<0.05)$. It implies that there is significant difference in the creativity level of hearing impaired students of Federal College of Education Oyo based on gender. Female hearing impaired students with higher mean of 65.54 significantly show a higher level of creativity than their male peer.

Ho3: There is no significant difference in the creativity level of hearing impaired students of Federal college of Education in Oyo based on onset of hearing impairment.

Level of creativity of hearing impaired students of Federal College of Education in Oyo on the basis of onset of hearing loss were compared using t-test statistics and the results are on Table 5.

Table 5

t-test analysis of Creativity level of hearing impaired students of Federal College of Education in Oyo based on onset of hearing impairment.

\begin{tabular}{llllllll}
\hline Variable & $\mathrm{N}$ & Mean & St.d & df & $\mathrm{t}$ & $\mathrm{p}$-value & Decision \\
\hline Pre lingua & 43 & 56.22 & 15.63 & & & & \\
\hline & & & & 58 & 1.885 & 0.015 & $\mathrm{~S}$ \\
\hline Post Lingua & 17 & 68.88 & 5.18 & & & & \\
\hline
\end{tabular}

Table 5 shows the calculated t-value 1.885 and its $\mathrm{p}$ - value is 0.015 at an alpha level of 0.05 , the null hypothesis three is rejected because the calculated p-value is less than 0.05 alpha level $(0.015<0.05)$. Therefore, creativity level of hearing-impaired students in Federal College of Education (Special) Oyo is significantly different on the basis of onset of hearing loss. The result shows that post-lingual hearing-impaired students with a higher mean (68.88) significantly show a higher level of creativity than their prelingual peer.

\section{DISCUSSION}

It was uncovered that innovativeness level of hearing and hearing-disabled students was both better than expected. This finding is reliable with the attestation of Osakwe (2010), insisted that regardless of the way disabled students are being defamed, their innovativeness capacity still remains undoubted. While the finding is against the 
submission of Olanrewaju, (2014) who observed hearing-impaired tertiary institution students in two states in Nigeria and discovered that they were poor in critical thinking.

A huge distinction was uncovered to have existed in the level of creativity of hearing and hearing-impaired students of Federal College of Education in Oyo. Creativity level of hearing-impaired students is essentially higher contrasted with their hearing peer. This could be that hearing-impaired students channel their powerlessness to use speech for social purposes to creative exercises. This finding is reliable with that of Ebrahim (2006) that deaf school-age children performed superior to hearing students in the aspects of fluency, adaptability, elaboration, and inventiveness. The discovering digresses from the perception of Ademokoya (1995) that the broad of poor thinking among students with hearing impairment can be credited to their listening ability loss and to the denying condition in which they regularly develop.

The study additionally uncovered that there is a huge contrast in creativity level of students of Federal College of Education in Oyo based on gender. Creativity level of female hearing impaired students./ is fundamentally higher than their male associate. The finding concurs with that of Olawuyi (2000) that there is a huge distinction in the thinking capacities of grade primary school pupils based on gender though however, the examination was completed among the primary school pupils. Additionally, Book (1972) saw that boys have a tendency to exceed expectations more in assignments that require creative thinking than girls. In the differentiation, Olanrewaju (2014) presented that there was no noteworthy distinction in the creative thinking of students with hearing impairment based on gender.

The finding further revealed that post-lingual hearing-impaired students are significantly higher in creativity level than their pre-lingua peer. Acquisition of communication skill by post-lingual hearing impaired students before sustaining hearing loss could account for their higher creativity level. This finding is in line with Olanrewaju, (2014) submission that there was a significant difference in the critical thinking skills of students with hearing impairment; post-lingual hearing disable significantly did better in critical thinking than their pre-lingual peer.

\section{CONCLUSION AND RECOMMENDATION}

It could be concluded from the results of this study that creativity level that is needed for three domains (cognitive, affective and psychomotor) in learning is quite beyond the expected (average). This is a signal that these groups of learners can attend the same school. In fact for the sake of effective teaching and learning process, they can be exposed to the same learning environment. They are both prepared academically and sociologically to undergo any form of classroom activities. Additionally, the creativity level of post-lingual hearing-impaired students is significantly higher than that of their pre-lingual peer.

In line with the results of this study, it was recommended that conventional approach of rendering education services used by Federal College of Education in Oyo should be reinforced and adopted in all institution where hearing and hearing-impaired students are present. 


\section{REFERENCES}

Ademokoya (2007). Onset of Hearing Loss, Gender and Self-Concept as Determinants of Academic Achievements in English Language of Students with Hearing Disability in Oyo State, Nigeria. Essays in Education. 22, 21-29

Ademokoya, J. A., (1995). Improving reasoning skills through direct and indirect instructional strategies. Unpublished Ph.D Thesis, University of Ibadan: Ibadan, Nigeria.

Ai, X. (1999). Creativity and Academic Achievement: An Investigation of Gender Differences. Creativity Research Journal, 12(4), 329-337.

Arehart, K. H. \& Yoshinaga-Itano, (1999). The Role of Educator of the Deaf in the Early Identification of Hearing Loss. American Annals of Deaf. 144, 19-23.

Baer, J., \& Kaufman, J. C. (2008). Gender Differences in Creativity. The Journal of Creative Behavior, 42(2), 75-105.

Bately, M., Furnham, A. (2006). Creativity, Intelligence, and Personality. A Critical Review of the Scattered Literature. Genetic, Social, and General Psychology Monographs, 132, 355-429. doi:10.3200/MONO.132.4.355-430

Best, J. W. \& Kahn, J. (2006) Research in Education: New Delhi: Prentice Hall of. India Pvt. Ltd.

Book, H. M. A. (1972). Psychological Analysis of Sex Differences. Journal of Society Psychology.3, 43-46.

Daramola, S. O. (2006). Research methods and statistical analysis in education. AdoEkiti: PETORA Educational publisher.

Ebrahim, F. (2006). Comparing Creative Thinking Abilities and Reasoning Ability of Deaf and Hearing Children Roeper. Review,28,140-147. doi:10.1080/02783190609554353

Hennessey, B. A. \& Amabile, T. M. (2010). Creativity. Annual Review of Psychology ,61, 569-598. doi: 10.1146/annurev.psych.093008.100416

Jonathan, P. (2002). Research and creative activity. Indiana University press. United States

Kaltsounis, S. B. (1971). Differences in Verbal Creative Thinking Abilities Between Deaf and Hearing Children. Child study journal, 1, 727-723.

Kaufmann, G. (2003). What to Measure? A New Look at the Concept of Creativity. Scandinavian Journal of Educational Research, 47,3, 235-251.

Kaufman, J. C., Baer, J., Cole, J. C., \& Sexton, J. D. (2008). A Comparison of Expert and Non-Expert Raters Using the Consensual Assessment Technique. Creativity Research Journal, 20, 171-178. 
Mba, P. O. (1991). Elements of special education. Ibadan: Cedars Publishing Company.

Mumford, S. I. \& Gustafson, A. (1988). Effectiveness of creativity training: A Quantitative Review. The University of Oklahoma, 8, 2, 12-15.

Okoye, N. N. (1987). Learners characteristics and human learning in school. In E.E. Ezewu (Eds.). Social psychological factors of human learning in school. Onitsha: Leadway Books Limited.

Olanrewaju, A. O. (2014). Analysis of critical thinking skills of students with hearing impairment in tertiary institutions in two states in Nigeria. Unpublished Masters Dissertation, University of Ilorin, Ilorin, Nigeria

Olawuyi, B. O. (2000). Effects of two training methods on the reasoning skills of hearing-impaired and hearing primary school pupils. Unpublished Ph.D Thesis, University of Ilorin, Ilorin, Nigeria.

ldham, G. R. \& Cummings, A. (1996). Employee Creativity: Personal and Contextual Factors at Work. Academy of Management Journal, 39, 607-634

Onwucheka, J. N. (1985). English Language performance of hearing and hearing impaired secondary school students. Unpublished Ph.D Thesis University of Wales, UK.

Osakwe, R. N. (2010). "Education for People with Special Needs in Nigeria: Challenges and Way Forward" in M. I. Atinmo, J. B. Babalola, O. A. Moronkola and A. I.

Atanda. Eds. Education for Sustainable Development. Faculty of Education, University of Ibadan, 33-43.

Sambo, A. A. (2008). Research methods in education. Edo: Stirling-Horden Publishers.

Sternberg, R. J., \& Lubart, T. I. (1999). The concept of creativity: Prospects and Paradigms. In R. J. Sternberg (Eds.), Handbook of creativity (pp. 3-16). London: Cambridge University Press.

The Research Advisors (2006). Sample size table. Retrieved from http://researchadvisors.com. 12/6/2015.

Ujo, A. A. (2000). Social research: a non- quantitative approach. Nigeria: Anyaotu enterprise and publisher ltd. 